\title{
TOPOLOGICAL AND GEOMETRICAL STRUCTURE OF CALDERÓN-LOZANOVSKIĬ CONSTRUCTION
}

\author{
PAWE€ KolWICZ AND KAROL LEŚNIK
}

Abstract. We study the structure of general Calderón-Lozanovskiŭ construction. First the problem of order continuity of these spaces is studied. Moreover, we find characterization of strict monotonicity and we try to explain why the obtained criteria are not easy to verify in particular cases.

Mathematics subject classification (2010): 46E30, 46B42, 46B20.

ity.

Keywords and phrases: Köthe space, Calderón-Lozanovskil̆ spaces, order continuity, strict monotonic-

\section{REFERENCES}

[1] M. A. AkCoglu, L. SuCheston, On uniform monotonicity of norms and ergodic theorems in function spaces, Rend. Circ. Mat. Palermo, II Ser., Suppl. 8 (1985), 325-335.

[2] G. BIRKHOFF, Lattice Theory, Providence, RI 1967.

[3] A. P. CALDERÓn, Intermediate spaces and interpolation, the complex method, Studia Math. 24 (1964), 113-190.

[4] S. CHEN, Geometry of Orlicz Spaces, Dissertationes Math. 356 (1996), 1-204.

[5] I. DobraKov, On submeasures I, Dissertationes Math. 112 (1974) 1-35.

[6] P. FORALEWSKI AND H. HUDZIK, On some geometrical and topological properties of generalized Calderón-Lozanovskil sequence spaces, Houston J. Math 25 (1999), no. 3, 523-542.

[7] H. HudZIK, A. KAMIŃSKA AND M. MASTYŁO, Geometric properties of some Calderón-Lozanovskiu spaces and Orlicz-Lorentz spaces, Houston J. Math. 22 (1996), 639-663.

[8] H. HudZIK, A. KAMIŃSKA AND M. MASTYŁO, Monotonicity and rotundity properties in Banach lattices, Rocky Mountain J. Math. 30 (2000), no. 3, 933-949.

[9] H. HUdZIK AND W. KURC, Monotonicity properties of Musielak-Orlicz spaces and dominated best approximation in Banach lattices, J. Approx. Theory 95 (1998), 353-368.

[10] H. HudZIK AND A. NARLOCH, Local monotonicity structure of Calderón-Lozanovskiŭ spaces, Indag. Math. N. S. 15 (2004), no. 1, 1-12.

[11] L. V. Kantorovich And G. P. Akilov, Functional Analysis, Nauka (Moscow, 1984) (in Russian).

[12] P. KolwiCZ, Rotundity properties in Calderón-Lozanovskiǔ spaces, Houston J. Math. 31 (2005), no. 3, 883-912.

[13] P. Kolwicz And R. PŁUCIENNIK, On uniform rotundity in every direction in Calderón-Lozanovski spaces, Journal of Convex Analysis 14, (2007), no. 3, 621-645.

[14] P. Kolwicz AND R. PŁUCIENNIK, Local $\Delta_{2}^{E}(x)$ condition as a crucial tool for local structure of Calderón-Lozanovskǐ spaces, submitted.

[15] S. G. KREIN, YU. I. PETUNIN AND E. M. SEMENOV, Interpolation of Linear Operators, Nauka, Moscow, 1978 (in Russian).

[16] W. KURC, Strictly and uniformly monotone Musielak-Orlicz spaces and applications to best approximation, J. Approx. Theory 69 (1992), no. 2, 173-187.

[17] L. Maligranda, Orlicz Spaces and Interpolation, Sem. Math. 5, Univ. of Campinas, Campinas SP, Brazil, 1989.

[18] L. Maligranda, L. E. Persson, Generalized duality of some Banach function spaces, Indag. Math. Proc. A 92 (1989), no. 3, 323-338.

[19] J. LindenSTRAUSS AND L. TZAFRIRI, Classical Banach Spaces II, Springer-Verlag (1979).

[20] G. YA. LoZAnOwsKIĬ, On some Banach lattices, Sibirsk. Math. J. 12 (1971), 562-567. 
[21] V. I. OvCHINNIKOV, Interpolation theorem resulting from an inequality of Grothendieck's, Functional Anal. i Prilozen 10 (1976), 45-54 (in Russian).

[22] S. REISNER, On two theorems of Lozanovskil concerning intermediate Banach lattices, Geometric Aspects of Functional Analysis (1986/87), Lecture Notes in Math. 1317, Springer Berlin 1988, 67-83.

[23] W. WNUK, Banach Lattices with Order Continuous Norms, Polish Scientific Publisher PWN, Warszawa 1999. 